\title{
Estimating the Causes of Poor Academic Performance of Students: A Case Study
}

\author{
Juwesh Binong \\ Department of Electronics \& Communication Engineering \\ North-Eastern Hill University \\ Shillong, India 793022
}

\begin{abstract}
Poor academic performance of students is not the only concern for parents and teachers, but also a concern for the country as a whole. This paper makes an attempt to identify the cause(s) of poor academic achievement. This paper presents a method of identifying the most influencing factor on academic performance. The proposed method capable of using qualitative ratings as input for the factors considered and find the correlation of each factor with academic performance, and finally rank the influences of the factors on performance to sort out the most influencing one. The study was carried out on the academic performance of 189 students of B.Tech for five academic semesters. The results indicate the degree influences of various factors on performance, with the most influencing one being the academic ability of students.
\end{abstract}

Keywords-Academic performance; qualitative rating; factors; correlation coefficient; analytic hierarchy process

\section{INTRODUCTION}

Good academic performance is very important for developing country like India $[1,2]$. By understanding the cause of poor academic performance, the concerned authority can take appropriate decision to improve academic performance or achievement of students [3].

The majority of the literature is, however, based on surveys $[4,5,6]$ and self-reports, methods which have well-known systematic biases that lead to limitations on conclusions and generality as well as being costly to implement.

Academic performance by a student is the result of various contributing factors. Literature lists multiple factors that affect academic performance of students. Academic performance is a complex equation with multiple angles. Effect of various factors on academic performance of students can not be denied.

Identifying the factors that influence academic performance is an essential part of educational research [7]. kassarnig et al. have shown that important indicators of academic performance are based on social ties. They confirm that class attendance stands as the most important predictor, but other factors like peer effect also influence on academic performance.

Attendance as a factor influencing a student's academic achievement is seen in literature. In [8] authors have demonstrated that consistent class attendance strongly correlates with academic achievement. They also demonstrated that their dataset allowed them to determine that attendance among social peers was substantially correlated $(>0.5)$, suggesting either an important peer effect or homophily with respect to attendance.
Credé et al. [9] have shown that class attendance and grades reveal a strong relationship with both class grades and GPA. According to their meta-analysis class attendance stands as a better predictor of college grades than any other known predictors of academic performance.

Influence of peers on academic performance cannot be denied. The peer effects start out from the assumption that human behavior is affected not only by personal and demographic features, but also the surrounding environment and to the individuals with whom he/she interacts [10].

The place of residence also plays an important role in students' academic achievement. Snyder et al. [11] concluded that living in an on campus or off campus environment had no statistical relationship with the academic performance of freshman student athletes. The study of Etikan et al. [12] suggested that there is no significant difference in the academic performance of the students residing on campus and outside the school environment, but found some influence on the choice of student accommodation preference.

The academic ability or intelligence is seen as an important factor on students' academic achievement. Intelligence is considered as the strongest predictor of academic achievement with correlations ranging from 0.30 to 0.70 [13]. They investigated the correlation between standardized intelligence tests and school grades using psychometric meta-analysis. The study results of Colom and Flores-Mendoza [14] indicate that socioeconomic status factors do not predict children differences in scholastic achievement, whereas children intelligence tests' scores predict their scholastic differences. These results underscore personal intelligence as a genuine predictor of individual differences in scholastic achievement. The association between intelligence and academic performance is well established in [15]. In [16], the authors showed the existence of a strong correlation between a latent intelligence trait and a latent trait of educational achievement.

Gbollie and Keamu [17] explored the motivational beliefs and learning strategy use by Liberian junior and senior high school students in connection with their academic performance.

Most of the factors influencing academic performance take qualitative data as input. A popular method that can accept qualitative input and ranks a set of factors is the analytic hierarchy process (AHP) [18], a popular Multiplecriteria decision-making (MCDM) method. AHP is a flexible but well-structured methodology for organizing and analyzing complex decisions [19], originally developed by Prof. Thomas 
L. Saaty [20]; and it is widely used in a wide variety of decision making situations, such as government, business, industry, shipbuilding, education, health-care, etc. [21, 22, 23].

AHP can be realized by three steps: 1) constructing the AHP hierarchy; 2) making a pairwise comparison of the elements of the hierarchical structure, and 3) aggregation of an overall priority rating to select the best candidate. In AHP human judgments can be used in performing the evaluations.

AHP has also been extended making it suitable to use with other mathematical methods including fuzzy logic. Yager and Kelman [24] extended the AHP by integrating the fuzzy linguistic ordered weighted averaging operators and thereby enhancing the capabilities of AHP as a comprehensive tool for decision-making. Li et al. [25] used the AHP with fuzzy inference technique in the dynamic route guidance system to provide dynamic routing advice based on real-time traffic information.

\section{A. Contribution}

The main contribution of this paper is a method that utilizes qualitative rating to study the influence of various factors on students' academic performance. As the method proposed follows the steps of AHP, it can accept approximate values as input, where getting an exact quantitative value is difficult or impossible.

The effectiveness of the proposed method is established using a dataset of more than one hundred students containing more than one three hundred records.

The rest of the paper is organized as follows. Section 2 formulates the problem. The data collection approach and the proposed method is discussed in Section 3. Experimental results and discussion on the outcomes are shown in Section 4. Finally, conclusion and future work are discussed in Section 5.

\section{PROBlem Formulation}

Factors affecting students academic performance can be categories based on various factors.

Considering the factors as variables the problem of students academic performance can be formulate as follows:

For a given dataset $D$ containing a parameter $R$ which is influenced by a set of features $\mathrm{F}=\left\{f_{1}, f_{2}, \cdots f_{n}\right\}$, the problem is to select an optimal feature $f_{x}$ that influence the most or a set of features with their amount of influences on $R$.

\section{MATERials AND MethodS}

\section{A. Candidates for the Study}

The candidates for this case study comprises of 312 academic records (percentage of marked obtained) of 189 students of B.Tech in Electronics \& Communications Engineering of North Eastern Hill University (NEHU), Shillong, India, covering academic years 2012-13, 2013-14, 2014-15 and 2015-16. Majority of the students belong to the Indian states of Assam, Meghalaya, other north eastern (Indian) states, and other parts of the country including West Bengal, Bihar, Uttar Pradesh etc. More than $80 \%$ of the students belong to Schedule Tribe and
Schedules Class categories. Of the population, $70 \%$ of students were male and $30 \%$ females, and in the age group of $17-21$ years.

\section{B. Factors Considered for the Study}

Poor academic performance may be the result of one or more factors. As seen from literature a number factors influence on academic performance. In this work only four factors are targeted; they are : academic ability, attendance, peers' effect and residential effect.

1) Academic Ability: Students' academic ability is taken as an important factor for this work, as the students considered for the research are from different parts of the neighbouring regions and they possess a wide range of past academic records.

2) Attendance: The percentage of course attendance of the students under consideration varies a wide range : very poor attendance as low as below $50 \%$ to a high of $100 \%$. This makes course attendance a possible cause of poor performance.

3) Peers' Effect: Peer effect is considered as a possible cause of poor academic performance as two or more students forming group of social life seem to achieve nearly same type of academic performance. It is observed that students sharing a common desk in the class or sharing social life inside and outside the campus generally obtain similar or nearly equal grades.

4) Residence Effect: The place of residence and its environment is taken as an influencing factor on academic performance. Students mostly reside in hostel inside the university campus and his/her social peer does not always share the same room. But it is seen that students sharing same room performing the same way in some cases.

\section{Data Collection}

Data of students academic achievements as well as of other factors were collected for the B.Tech students of Electronics and Communication Engineering, North Eastern Hill University (NEHU), Shillong, India.

The percentage obtained by the students of B.Tech in Electronics \& Communications Engineering in their end semester examinations was collected from the department. Data field for hostel residential information was collected from hostel wardens and roommate quality was assigned based on his/her academic achievement. Information about peer was collected from their friend circle and teachers. Collection of peers' information was not very difficult as the students belong to our department.

At the university, course attendance of $75 \%$ is mandatory to be eligible to appear in the end semester examination.

In terms of privacy of candidates considered for the study their identity have been changed.

\section{Assigning Qualitative Rating}

Other than the percentage of attendance, most of the factors considered for the study possesses no quantitative value. What one can get for these factors is qualitative value as input. For 
example, peer of a student can be bad or good. Similarly a hostel mate may a good or a bad one. Qualitative rating for the factors considered was assigned as given in the following:

1) Academic Achievement: The academic achievement of a student was considered in term of the CGPA (overall percentage of marks) obtained for each subject in the end semester examination.

The percentage of marks obtained by the students were converted to equivalent percentage range. Based on the performance in each subject in a semester, qualitative ratings were assigned to a student for each subject using Table I.

TABLE I. QUALITATIVE RATING FOR ACADEMIC PERFORMANCE

\begin{tabular}{c|l}
\hline Percentage Secured & Qualitative Rating \\
\hline $90-100$ & Very Good performance \\
\hline $70-89$ & Good performance \\
\hline $50-69$ & Average performance \\
\hline $30-49$ & Poor performance \\
\hline less than 30 & Very Poor performance \\
\hline &
\end{tabular}

Scores were assigned to the qualitative rating obtained based on the intensity of achievement. The use of such score has advantages over grade obtained by students because a student who fails get ' $F$ ' grade which equals 4 in 10 point scale and can not consider lower grade than 4.

The qualitative rating used to measure the qualities and the corresponding score for various factors are presented in Table II.

TABLE II. QUALITATIVE RATING \& RATING SCORE USED

\begin{tabular}{r|l}
\hline Qualitative Rating & Rating Score \\
\hline Very Good & 9 \\
Good & 7 \\
Average & 5 \\
Poor & 3 \\
Very Poor & 1 \\
\hline &
\end{tabular}

2) Qualitative Rating for Academic Ability: An absolute judgment of academic excellence of a student in term of some number always does not give a correct judgment. Students with the same percentage but from different universities may be not of the same academic ability or excellence. Hence, students' academic ability given in term of percentage are rated using qualitative rating. Students' academic ability was rated based on their past performance as shown in Table III.

Past academic achievement by a student was considered as a factor to judge the academic ability of a student. The grade obtained by a student in the lower semester were used as past academic performance. Though grade obtained in class- $X$ and
class-XII would be the ideal choice, were not use because of non-availability of data.

TABLE III. Qualitative Rating on ACADEMic AbILity of Students

\begin{tabular}{r|l}
\hline Qualitative Rating & Meaning \\
\hline Very Good academically & Student securing marks $90 \%$ or above \\
\hline Good academically & Student securing marks between $80-89 \%$ \\
\hline Average academically & Student securing marks between $70-79 \%$ \\
\hline Poor academically & Student securing marks between $60-69 \%$ \\
\hline Very Poor academically & Student securing marks between $45-59 \%$ \\
\hline &
\end{tabular}

3) Qualitative Rating for Attendance: Attendance percentage acquired by students for a subject is taken as an indicator of self-motivation. Attendance roughly represents a parameter of motivation. As two equal percentage of attendance generally do not represent the same of amount of motivation of two students, percentage of attendance acquired by students was transformed into grading scale as shown in Table IV. The rating has been taken a non-equal division approach as generally academic achievement does not follow a linear division.

TABLE IV. QUALITATIVE RATING ON ATTENDANCE

\begin{tabular}{r|l}
\hline Qualitative Rating & Meaning \\
\hline Very Good attendance & Securing attendance 95\% or above \\
\hline Good attendance & Securing attendance between $85-94 \%$ \\
\hline Average attendance & Securing attendance between $75-84 \%$ \\
\hline Poor attendance & Securing attendance between $60-74 \%$ \\
\hline Very Poor attendance & Securing attendance below $60 \%$ \\
\hline &
\end{tabular}

4) Qualitative Rating for Peers' Effect: Assigning quantitative values to measure the quality of a student's peer is not logical. Generally we humans use qualitative terms like 'good', 'very good', 'bad', 'very bad' etc to refer the quality of one's friend. So qualitative terms were used to refer to the quality of a student's peer. A qualitative score was awarded to a student base on the performance of his/her peer with whom the student spends most of the times; and rating is shown in Table V. For example, if ' $\mathrm{Y}$ ' is the peer of ' $\mathrm{X}$ ', and academic performance of ' $\mathrm{Y}$ ' is good, ' $\mathrm{X}$ ' receives higher score.

5) Qualitative Rating for Residence Effect: Assigning quantitative values to measure the quality of a student's roommate is not logical as in the case of peer effect. Hence, a qualitative score was awarded to a student base on the academic performance of his/her roommates. The rating is shown in Table VI.

Students residing with parents were assigned 'very good' rating assuming a favourable condition at home; and students residing in shared accommodation in rented house were 
TABle V. Qualitative Rating on Peers' EfFect

\begin{tabular}{r|l}
\hline Qualitative Rating & Meaning \\
\hline Very Good Peer & $\begin{array}{l}\text { Very good academic performance } \\
\text { by his/her peers }\end{array}$ \\
\hline Good Peer & $\begin{array}{l}\text { Good academic performance by } \\
\text { his/her peers }\end{array}$ \\
\hline Average Peer & $\begin{array}{l}\text { Average academic performance } \\
\text { by his/her peers }\end{array}$ \\
\hline Poor Peer & $\begin{array}{l}\text { Poor academic performance by } \\
\text { his/her peers }\end{array}$ \\
\hline Very Poor Peer & $\begin{array}{l}\text { Very poor academic performance } \\
\text { by his/her peers }\end{array}$ \\
\hline &
\end{tabular}

TABLE VI. QUALITATIVE RATING ON RESIDENTIAL EFFECT

\begin{tabular}{c|l}
\hline Qualitative Rating & Meaning \\
\hline Very Good Residence & $\begin{array}{l}\text { Very good academic performance } \\
\text { by his/her roommates }\end{array}$ \\
\hline Good Residence & $\begin{array}{l}\text { Good academic performance } \\
\text { by his/her roommates }\end{array}$ \\
\hline Average Residence & $\begin{array}{l}\text { Average academic performance } \\
\text { by his/her roommates }\end{array}$ \\
\hline Poor Residence & $\begin{array}{l}\text { Poor academic performance } \\
\text { by his/her roommates }\end{array}$ \\
\hline Very Poor Residence & $\begin{array}{l}\text { Very poor academic performance } \\
\text { by his/her roommates }\end{array}$ \\
\hline &
\end{tabular}

awarded rating using Table VI to consider the effect of roommates.

\section{E. Ranking of Factors}

Getting true quantitative values for the listed factors are difficult and almost impossible. There are chances of being erroneous or biases of these values. AHP hold promises in such situation by accepting qualitative values as input. The following steps were performed in determining the most important one among the factors.

1) Calculating Correlation Coefficients: Correlation coefficient of two random variables, say $\mathrm{X}$ and $\mathrm{Y}$ shows how strongly the values of these variables are related to one another. The Pearson's correlation coefficients $\rho_{X Y}$ of two random variables $X$ and $Y$, denoted by $\operatorname{Corr}(X, Y)$ or $\rho_{X, Y}$ is given by [26] as:

$$
\rho_{X Y}=\frac{\Sigma\left(x_{i}-\bar{x}\right)\left(y_{i}-\bar{y}\right)}{\sqrt{\Sigma\left(x_{i}-\bar{x}\right)^{2} \Sigma\left(y_{i}-\bar{y}\right)^{2}}}
$$

where $x_{i}$ and $y_{i}$ are the values of random variables $X$ and
$Y$ for $i=1,2, \cdots, n$; and $\bar{x}$ and $\bar{y}$ are the means of $x_{i}$ and $y_{i}$ respectively.

If $\left\{f_{1}, f_{2}, \cdots f_{n}\right\}$ are factors influencing the academic performance $\gamma$, the Pearson's correlation coefficients $\rho_{1, \gamma}, \rho_{2, \gamma}$, $\cdots \rho_{n, \gamma}$ for each of the factors with the academic performance $\gamma$ is calculated using equation 1 .

2) Decision Matrix and Ranking of Factors: Correlation coefficient obtained for four different factors were used to access the strength of the judgments. Based on the rating obtained from the rating assignment process, decision matrix [27] was formed and the factors were prioritized by calculating their normalized scores using the three steps as follows:

1) Making of the decison matrix

2) Normalization of each column of the decision matrix

3) Row-wise summation and normalization of rowsums.

Step 1: The decison matrix $M$ is constructed as shown in Equation 2:

$$
\left.M=\stackrel{\rho_{1}}{\rho_{1}} \begin{array}{ccccc}
\rho_{1} & \rho_{2} & \rho_{3} & \ldots & \rho_{n} \\
\rho_{n} & x_{12} & x_{13} & \ldots & x_{1 n} \\
x_{21} & x_{22} & x_{23} & \ldots & x_{2 n} \\
\ldots & \ldots & \ldots & \ldots & \ldots \\
x_{n 1} & x_{n 2} & x_{n 3} & \ldots & x_{n n}
\end{array}\right]
$$

where each element of the matrix is a ratio of the two correlation coefficients, such as $x_{11}=\frac{\rho_{1}}{\rho_{1}}, x_{12}=\frac{\rho_{1}}{\rho_{2}}$, $\cdots, x_{n n}=\frac{\rho_{n}}{\rho_{n}}$.

Step 2: The column sum of the decision matrix (Equation 2) is calculated for each column and each element of the matrix is normalized to get the matrix shown in Equation 3.

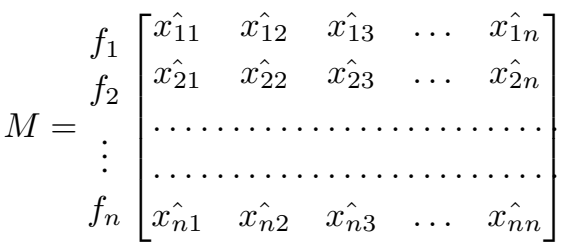

Step 3: The row sum of the matrix (Equation 3) is calculated to get a column matrix as shown in Equation 4.

$$
M=\stackrel{f_{1}}{f_{2}}\left[\begin{array}{c}
\sum \hat{x_{1 n}} \\
\vdots \\
f_{n} \\
\cdots \\
\cdots \\
\sum \hat{x_{n n}}
\end{array}\right]=\left[\begin{array}{c}
S\left(\rho_{1}\right) \\
S\left(\rho_{1}\right) \\
\cdots \\
\cdots \\
S\left(\rho_{n}\right)
\end{array}\right]
$$

$S\left(\rho_{1}\right), S\left(\rho_{1}\right), \cdots, S\left(\rho_{n}\right)$ are the normalized scores and these values specify the intensity of influence of factors on academic performance, and hence the ranking of the factors are obtained.

Algorithm 1 describes the process of computing the ranks of the factors based on the amount of its influencing on the academic performance. 


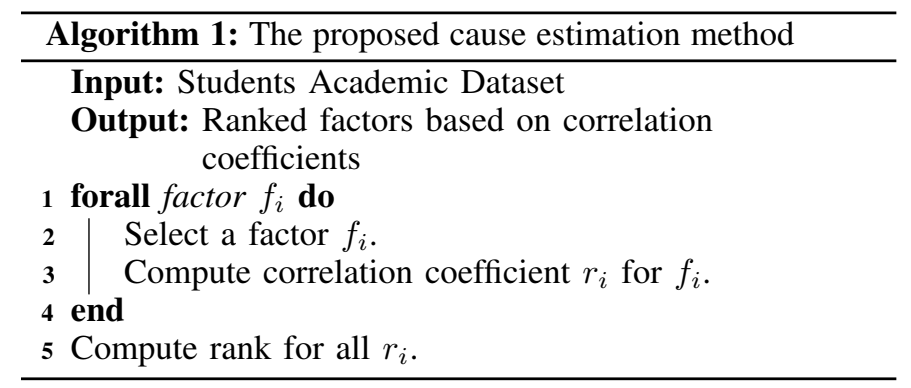

\section{RESUlTS AND Discussion}

In the following the influence of various factors on the academic achievement of students are analysis. The results of the expereimentation are discussed first, followed by the discussion on the results.

\section{A. Results}

The correlation coefficients of each factors with the academic performance score of the students were calculated using Equation 1, and are shown in Table VII.

TABLE VII. CORRELATION COEFFICIENTS OBTAINED FROM THE DATASET

\begin{tabular}{c|c|c|c|c}
\hline factors & Academic Ability & Attendance & Peers' Effect & Residence Effect \\
\hline$\rho$ & 0.5480 & 0.3305 & 0.3297 & 0.3364 \\
\hline
\end{tabular}

1) Academic Ability: Result showed that correlation between student academic ability and student academic performance has a strong relation. Academic performance almost linearly increases with student's academic ability (see Fig. 1).

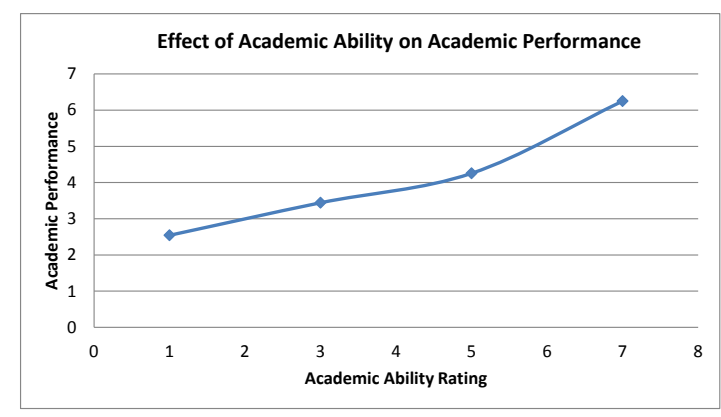

Fig. 1. Effect of academic ability on academic performance

2) Peers Factor: Effect of peers reveals a strong relation on student academic performance as shown in the result (see Fig. 2). The performance of students shows an almost linear effect on the performance of students. Quality of peer shows significant impact on one's academic performance.

3) Residence Factor: Effect of residence on academic performance of students shows impact under certain condition. The poor residential condition shows poor in academic performance, but after certain level, this factor shows no effect as indicated by an almost horizontal line for better residential conditions (see Fig. 3).

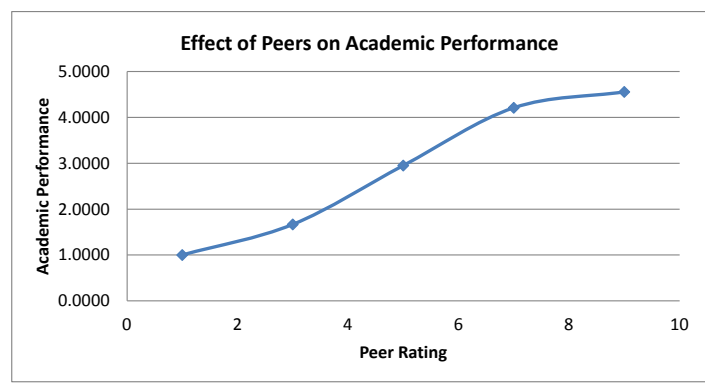

Fig. 2. Effect of peers on academic performance

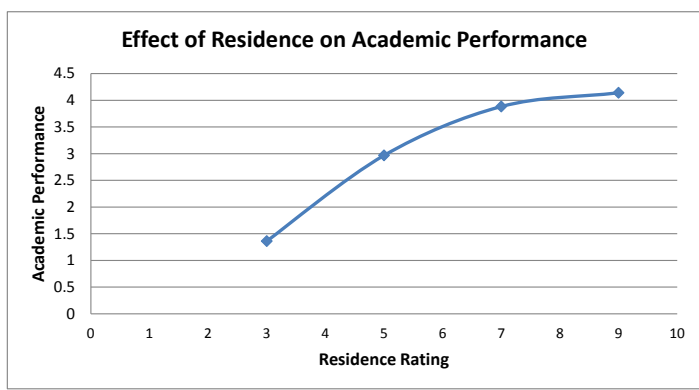

Fig. 3. Effect of residence on academic performance

4) Attendance Factor: Correlation is strongly significant with very low attendance $(\leq 50 \%)$. As reported in literature the impact of attendance on the academic performance of students is clearly visible from the plot (see Fig. 4).

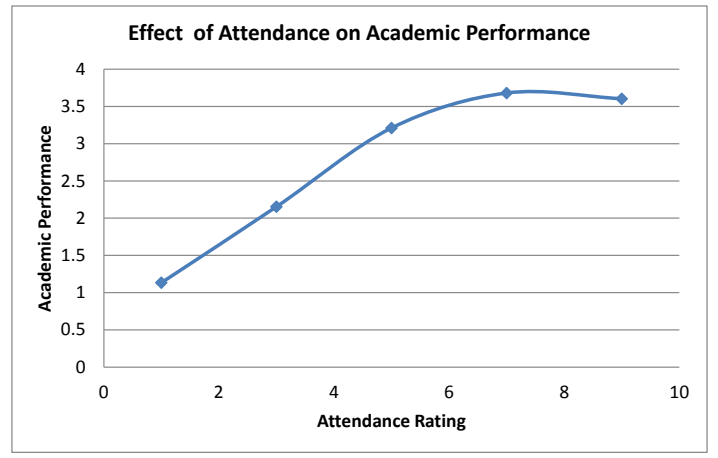

Fig. 4. Effect of attendance on academic performance

5) Decision Matrix: The final normalized scores of the factors as obtained from the decision matrix are shown in Table VIII. These scores specify the intensity of influences of the factors on the academic performance.

TABLE VIII. NORMALIZED SCORES OBTAINED FROM THE DECISION MATRIX

\begin{tabular}{c|c|c|c}
\hline Academic Ability & Attendance & Peers' Effect & Residence Effect \\
\hline 0.3550 & 0.2157 & 0.2151 & 0.2142 \\
\hline
\end{tabular}




\section{B. Discussion}

Based on the experimentation, it is observed that academic ability of a student influence strongly in his/her academic achievement with score 0.3550 . For achieving good academic performance a student with good academic ability is reqired. The result indicates that the effect of academic ability on performance shows a complex pattern: for poor and good performing students it shows a strong relation, while for average students the effect is less pronounced.

Influence of peers' quality is found to have an almost linear effect on academic achievement. A very bad peer contributes to a very poor academic achievement. A poor residential environment also shows a significant negative effect on one's academic achievement. This factor shows less or no influence under a good residential environment, but this effect holds strong for the low residential condition. Interestingly, this effect vanishes under a good and a very good residential environment.

A general decreasing trend of attendance curve indicates a strong effect of attendance on academic achievement. Lower the attendance is higher the effect on the achievement and higher the attendance is lower the effect. The attendance percentage shows a strong relation on fail; the effect becomes less pronounced at higher percentage of attendance.

The most influencing factor can not be the universal one. Other factor may be the most influencing one in different conditions and in different institute.

\section{CONCLUSION AND Future WORK}

The paper has demonstrated the connection between academic performance and various factors, and shown how different factors influence on the performance, and also the effect of the factors are ranked to arrived at the most influencing one. The proposed approach can be enhanced by considering more factors effecting on academic performance.

The proposed method has shown that this method can be utilized to access students' performance factors for cases having difficulty in getting quantitative data as input. But, more into inside students social behaviours and daily life are required to get detailed knowledge regarding the individuals students so as to able to assign a correct qualitative rating.

Results with different factors indicate that students' academic ability is an important factor for students' academic achievement, but other factors influence on academic performance as well. Further research is may be done to understand to what extent these factors influence students' academic success.

The study can be performed on a bigger dataset with more information.

\section{REFERENCES}

[1] Bhise, R., Thorat, S., and Supekar, A. Importance of data mining in higher education system. IOSR Journal Of Humanities And Social Science (IOSR-JHSS), pages 2279-0837, 2013.

[2] Osmanbegović, E. and Suljić, M. Data mining approach for predicting student performance. Economic Review, 10(1):3-12, 2012.
[3] Romero, C. and Ventura, S. Educational data mining: a review of the state of the art. IEEE Transactions on Systems, Man, and Cybernetics, Part C (Applications and Reviews), 40(6):601-618, 2010.

[4] Banerjee, P. A. A systematic review of factors linked to poor academic performance of disadvantaged students in science and maths in schools. Cogent Education, 3(1):1178441, 2016.

[5] Al-Zoubi, S. M. and Younes, M. A. B. Low academic achievement: causes and results. Theory and Practice in Language Studies, 5(11):2262, 2015.

[6] Wilder, S. Effects of parental involvement on academic achievement: a meta-synthesis. Educational Review, 66(3):377-397, 2014.

[7] Kassarnig, V., Mones, E., Bjerre-Nielsen, A., Sapiezynski, P., Dreyer Lassen, D., and Lehmann, S. Academic performance and behavioral patterns. EPJ Data Science, 7:1-16, 2018.

[8] Kassarnig, V., Bjerre-Nielsen, A., Mones, E., Lehmann, S., and Lassen, D. D. Class attendance, peer similarity, and academic performance in a large field study. PloS one, 12(11):e0187078, 2017.

[9] Credé, M., Roch, S. G., and Kieszczynka, U. M. Class attendance in college: A meta-analytic review of the relationship of class attendance with grades and student characteristics. Review of Educational Research, 80(2):272-295, 2010.

[10] Celant, S. The analysis of students' academic achievement: the evaluation of peer effects through relational links, 2013. Quality \& Quantity, 47(2):615-631, 2013.

[11] Snyder, E. M., Kras, J. M., Bressel, E., Reeve, E. M., and Dilworth, V. The relationship of residence to academic performance in ncaa division $\mathrm{i}$ freshman athletes. Journal of issues in intercollegiate athletics, 4:105119, 2011.

[12] Etikan, I., Bala, K., Babatope, O., Yuvalı, M., and Bakır, I. (2017). Influence of residential setting on student outcome. Biom Biostat Int J, 6(4):00177, 2017.

[13] Roth, B., Becker, N., Romeyke, S., Schäfer, S., Domnick, F., and Spinath, F. M. Intelligence and school grades: A meta-analysis. Intelligence, 53:118-137, 2015.

[14] Colom, R. and Flores-Mendoza, C. E. Intelligence predicts scholastic achievement irrespective of ses factors: Evidence from brazil. Intelligence, 35(3):243-251, 2007.

[15] Soares, D. L., Lemos, G. C., Primi, R., and Almeida, L. S. The relationship between intelligence and academic achievement throughout middle school: The role of students' prior academic performance. Learning and Individual Differences, 41:73-78, 2015.

[16] Deary, I. J., Strand, S., Smith, P., and Fernandes, C. Intelligence and educational achievement. Intelligence, 35(1):13-21, 2007.

[17] Gbollie, C. and Keamu, H. P. Student academic performance: The role of motivation, strategies, and perceived factors hindering liberian junior and senior high school students learning. Education Research International, 2017

[18] Saaty, T. L. The Analytic Hierarchy Process. New York: McGraw-Hill, 1980.

[19] Saaty, T. L. What is the analytic hierarchy process? In Mathematical Models for Decision Support, pages 109-121. Springer, 1988.

[20] Saaty, T. L. A scaling method for priorities in hierarchical structures. Journal of Mathematical Psychology, 15(3):234-281, 1977.

[21] Saaty, T. L. Decision making with the analytic hierarchy process. International journal of services sciences, 1(1):83-98, 2008.

[22] Fong, P. S.-W. and Choi, S. K.-Y. Final contractor selection using the analytical hierarchy process. Construction Management \& Economics, 18(5):547-557, 2000.

[23] Saracoglu, B. O. Selecting industrial investment locations in master plans of countries. European Journal of Industrial Engineering, 7(4):416-441, 2013.

[24] Yager, R. R. and Kelman, A. An extension of the analytical hierarchy process using owa operators. Journal of Intelligent \& Fuzzy Systems, 7(4):401-417, 1999.

[25] Li, C., Anavatti, S. G., and Ray, T. Analytical hierarchy process using fuzzy inference technique for real-time route guidance system. IEEE Transactions on Intelligent Transportation Systems, 15(1):84-93, 2014.

[26] Lee Rodgers, J. and Nicewander, W. A. Thirteen ways to look at the correlation coefficient. The American Statistician, 42(1):59-66, 1988.

[27] Yang, J.-B. and Xu, D.-L. On the evidential reasoning algorithm for multiple attribute decision analysis under uncertainty. IEEE Transactions on Systems, Man, and Cybernetics-Part A: Systems and Humans, 32(3):289304, 2002. 